Molecules 2003, 8, 2-12

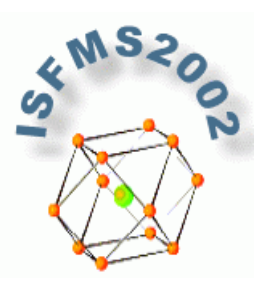

molecules

ISSN 1420-3049

http://www.mdpi.org

Science and Society Lecture

\title{
The Societal Obligations of Universities
}

\section{Richard R. Ernst}

Laboratory of Physical Chemistry, ETH Zentrum, CHN, CH-8092 Zurich, Switzerland. Telephone: (+41)-1-632 4368; Fax: (+41)-1-632 1257; E-mail: ernst@phys.chem.ethz.ch

The questions I will discuss in my lecture are not specific to China, but rather apply to any country on the globe. They concern the relation between the academic community and society. Naturally, much of the hope for a better future is directed towards the sciences which provide the foundation for prosperous industries and for a higher standard of living. Without advanced and competitive science, nothing functions in any country, and adequate science support will be essential also for a healthy development of China.

But the technological development has also its darker sides. The incessant destruction of the environment and the overexploitation of resources are well known. Often these aspects are disregarded in favour of rapid progress. Even the rich United States take short-sighted decisions in order to foster a prosperous industry today, not thinking about the consequences tomorrow. I am sure that similar temptations could also arise in other countries which have to struggle much harder in order to succeed on the world market. In such a situation, it could easily happen that the adverse effects of technology could dominate its benefits.

It is indeed imperative to thoughtfully select the sciences to be promoted. The most important selection criterion is the availability of highly creative scientists in a particular domain. Without top scientists, no field can prosper, irrespective of the allocated financial means. The national priorities must take the available human scientific capital into account. Secondly, the scientists themselves must select their research goals in view of the long-term societal needs. Even very fundamental research can in this way be justified. But the scientists are challenged to find links from their esoteric research to the societal reality. 
I will concentrate my lecture on the role the universities have to play in paving our avenue into the future. I will speak about responsibilities and about tasks which I think our universities and the academic community should take today more seriously than they did in the past.

Soon you will find out that I have more questions to pose than answers to give. This is not surprising! Nobody has ultimate solutions for our perennial questions, and also in the future, we will have to struggle on a day by day basis, hoping that our civilization lasts a little bit longer than the most pessimistic predictions like to tell us. But nevertheless, long-term foresight is indispensible.

\section{Who is Providing the Indispensible Long-term Foresight?}

One might visualize our destiny as a vehicle with the society as passengers, kept in a good mood by politicians. The vehicle possesses a strong power wheel, representing industry, that pushes the vehicle forward - but who is piloting our vehicle, who is defining the direction to go? Is there some irrevocable destiny? Or is it just the powerful engine that drives us without any guidance straight into the disaster? Or is it the society itself that decides democratically by a majority vote on the goal of our jolting trip?

I see serious problems regarding guidance. First, I doubt that politicians can find the necessary leisure for true long-term visions. Their agenda is overflooded with short-term obligations. They are often challenged to accomplish the impossible task of finding compromises between various party extremes.

Our industrial leaders provide a lot of initiative and drive, but also have hardly enough leisure for conceiving and implementing long-term visions. Certainly, we urgently need enterprising spirits, but business leaders are operating on extremely narrow margins, and are under constant pressure from the shareholders to optimize the short-term profits. And the speed of change they have to master is becoming more and more scaring and inhumane. So who remains to provide responsible long-term leadership? The NGO's certainly fulfill an essential function, but they act more as critics and warners and often, they are not taken sufficiently seriously as they tend to express extreme opinions - but who else? - It is for me more than clear that the universities and the academic community, in general, are predestinate to have a major responsibility in long-term guidance.

Let us hear how the former President of Cornell University, Frank H.T.Rhodes has formulated the task of the 'New University': "In an era of broken families, dwindling religious congregations, decaying communities, our nation desperately needs a new model of community - knowledgeable but compassionate, critical but concerned, skeptical but affirming - that will serve the clamoring needs of our fragmented society and respond to the nobler, unuttered aspirations of our deeper selves. This 
emerging community will be the New University."

Frank H.T. Rhodes is convinced that the university has an obligation that goes much beyond scientific research and professional education. I fully agree. Of course, progress is only possible based on novel insights into the secrets of nature and on ingenious inventions. Scientific research on the highest conceivable level and in the most minute details is truely indispensible. - Of course, industry depends on well educated specialists who know their trade better than everybody else, and our scientific tradition at the universities can also not be continued without young scientists full of creative ideas. Research and education remain the two pillars which justify the costly university enterprises. Nevertheless, I think that the most fundamental obligation for which universities are supported generously by the society is to safeguard a long-term prosperous future of the global human population.

So let us turn our universities again into into creativity centers with a broad view encompassing our entire global civilization! - But are we still the elite which we pretend to be? Didn't we rather become extremely skilful super-technicians who have lost the wisdom and the foresight to provide guide-lines for the global development? Let us hear again Frank H.T. Rhodes: "The sciences have become powerful, but increasingly unintelligible to nonscientists. The social sciences, entranced by microanalysis and quantification, have become increasingly irrelevant to social issues and public policy. The humanities, embracing fragmentation, otherness, and unreality have neglected the great overarching issues of human commonality." We have to keep these facts in mind when we want to address the general public.

\section{Autonomy and Responsibility}

From their beginning, a thousand years ago, the universities have enjoyed much independence from the state and the religious establishments. Even more autonomy has been granted recently and still more is demanded today by the university community. It is indeed time to think about novel forms for the future university. More independence and more responsibility shall be given to the universities. But more autonomy implies also more responsibility and to undertake voluntarily what needs to be done. Those who are granted freedom have to do deliberately what is expected from them. In other words, the burden of obedience is replaced by the burden of responsibility.

I see responsibilities of the new university in four domains, at first the traditional ones: scientific research and student teaching, and then those on which I would like to put particular emphasis in my lecture:

(i) Responsibility in Research: I do not have add much about research to what I stated at the beginning of this lecture. Science brought us to where we are today. Science supports us daily, and science will lead us into the future. Of course, scientific research is expected be first class and 
internationally competitive. Otherwise, it would do more harm than good. Quality and originality come first. But research must also make sense, in a way which can be conveyed to a lay person. A scientist who can not make himself understand able with regard to his motivation and his goals either does not comprehend the relevance of his work himself, or the work is truely irrelevant.

Scientists have to learn to be communicators. Otherwise society could stop investing into what they might consider to be 'black holes on two legs'. Science is supported by society in the expectation of serving a public purpose that can be justified, and the scientific activities should not be idling just to mutually please the members of a science club. This does in no way imply exclusive support of applied research, in contrary, the society expects the scientists to look far ahead into the future and think about the needs of the public in ten, twenty, or even fifty years, and this well justifies the promotion of research as basic as ever possible.

Scientific stimulation can come from the basic human curiosity to understand the world. It may also have its origin in the recognition of a need and a feeling of responsibility towards society. But it should never be induced by seducing grants. I have been skeptical about state-programmed research for a long time.

Efficient research support has much to do with the proper encouragement of creative individuals, especially of young, promising scientists. Enhancing mobility and exchange of students and researchers is more effective than enforced politically motivated collaboration. Generous travel grants are essential for enhancing international collaboration. This leads us to the second responsibility:

(ii) Education of Scientists and Responsible Leaders: James J. Duderstadt, the former President of the University of Michigan said: "There is a growing recognition that few public investments have higher economic payoff than those made in higher education." Obviously, industry and society expect from us the formation of the very best, most knowledgeable, and most creative specialists in our fields of expertise. This will remain the university's main objective also in the future.

I am sure we could do a much better job than so far when we would once start to renovate our middle-aged classroom teaching methods. Already Albert Einstein noticed, probably during his studies in Zurich: "It is nothing short of a miracle that the modern methods of instruction have not yet entirely strangled the holy curiosity of enquiry." Indeed, hands-on experience is much more valuable than sitting listening in an overcrowded lecture room. A successful teacher is not so much a lecturer but an inspirator and advisor. The inspired students have then to learn by themselves in the laboratory or in small discussion groups. But this is not the subject I wanted to cover here.

At least as important as factual teaching, I consider our duty to open the eyes our students for global long-term aspects and for the interconnection between our science and seemingly unrelated 
events and developments within society. Indeed what we need most urgently are true leaders who recognize long-term consequences and who are willing to carry responsibility in a way I will sketch under point (iv). If we want to influence the course of the global development, we have to start by educating young leaders who will act as ambassadors wherever they will be active, in industry, in politics, or in any other domain of society. Then we can hope for a long-term multiplying effect. This leads us to the third point:

(iii) Responsibility of Public Teaching: I do not think that we have completed our teaching obligations by the formation of knowledgeable and responsible specialists alone. University teachers have to become active in spreading basic scientific knowledge within the society. Each and every citizen should possess the necessary knowledges to behave properly in view of a sustainable and considerate future development on our globe. Sustainability can not be enforced by even the strictest laws but requires a sufficient under standing of some basic scientific facts by everybody. In this view, our teaching obligations go far beyond the doors of our universities.

Indeed the public ignorance and the susceptibility to false doctrines is sometimes frightening, even in our sometimes admired model country, the United States where nine years ago still $47 \%$ of all citizens believed in creation having happened during the past 10,000 years! Indeed, the communication gap between science and society might become decisive for the future of humankind. Sometimes, I have the impression that society is on a night flight, having lost ground and not knowing where to go, leading with almost certainty to a preprogrammed cash landing. We should also recognize that our fate depends very heavily on the progress of education in the developing countries. Our contributions in this field would be very welcome.

Many ways are conceivable to become active outside of the doors of the university:

- Writing of popular science articles in newspapers and magazines.

- Initiating scientific radio and TV broadcasts.

- Public science debates.

- Occasional lecturing in highschools.

- Preparation of distant learning courses on the internet.

- Regular or occasional contacts to politicians.

But all these additional activities require some of our precious time and are impossible without some shift of our priorities.

(iv) Conceptual Societal Responsibility: All I have said so far about responsibility is somewhat in the air unless there is some accepted foundation on which we can build. But what are the true foundations of our society and economy today? - Most of the traditional ethical systems related to religions and 
pseudo-religions are partially broken down. We are left alone with the concepts of free market economy and its measure of success, the share-holder-value. Maximizing profits is the goal, and we are expected to exploit all conceivable legal and semi-legal means. We all became passionate stock market gamblers. And it is the 'golden calf' that we adore. No ethics, no moral, no responsibility are left! The U.S. are the forerunners in this respect, and we in Europe and Asia, we have to run faster to catch-up! But are we running in the proper direction? This question is very seldom asked nor answered.

The rational appeal of our economic system is hard to deny. In principle it consists of a network of feedback loops and fringe conditions which reflect the market response, the costs, the laws. And the measure that is optimized are the profits reflected in the share-holder value.We are following Darwin's principle which was so successful in the development of nature. We would not be here without. It is a democratic system. Everybody has initally the same chances and those who do not take advantage of them, might have to suffer from their own faults. As George W. Bush says: The poor are poor by their own choice! The system is just and non forbidding. You get what you deserve, like the dinosaurs that were extinguished! There are no limits of growth of personal wealth, and there are hardly any limits of personal failure. There is no 'better' system conceivable!

Is this really all true? For example, does really everybody have the same initial chances? For example those who choose to be born into a poor family, or those who choose to be born in a developing country by an AIDS -infected mother? No, the initial chances can be enormously different! There is no justice in this respect. And how about the chances of the generation born in 100 years in comparison to our own chances when we have used up all the crude oil reserves? Is there anything left when they want to start a decent life? And if somebody has failed, will he or she have a second chance? Economical success is a highly non-linear affair. The start may be very difficult, but when you have once your first 100 millon US\$, it may be much easier to raise the second one. If one looks at the economical system in this way, one finds very little fairness and equality built in.

Perhaps, indeed, we have to start thinking in academic circles about smaller or larger changes to conceive instead of the 'free market system' a 'responsible market system'.

\section{Some Specific Relevant Issues}

1. Sustainability: Our economical system is governed by the immediate positive or negative effects of a measure taken. The reaction of the consumer determines the next immediate action. For example, the production of shoes that cause invariably blisters can not be maintained for a long time. The reaction of customers can be quite rapid, and a little bit of market research or counting the left-overs on the shelfs in a supermarket is all that is needed for guiding a production plant in the proper direction. The free market feedback mechanisms are functioning well for the optimization of commercial products. 
On the other hand, the reaction of the environment can be exceedingly slow in comparison to the turnaround time of a product. Often, the devasting effects, that are caused, become apparent only generations later. Heavy penalties would have to be built purposely into the economical system to limit such adverse environmental effects. One could perhaps distinguish three different standpoints in this regard:

(i) Après moi le déluge! Let us enjoy what nature has generously prepared for us! So far, we did not reach any real limits and should not care.

(ii) Penalties shall be incorporated into the economical system such that they prevent the worst excesses in misusing the environment, but without seriously affecting our business and prosperity.

(iii) The penalties are chosen to be sufficiently high so that the collected revenues allow for a complete reconstitution of the damaged natural environment whenever desired, irrespective of the possible consequences on economy.

Today, we adhere to a combination of the standpoints (i) and (ii). But in principle, only the extreme standpoint (iii) is morally acceptable. It truly leaves equal chances to the future generations. For example in the case of the exploitation of fossil fuels, the tax rates should be suffie ntly high to reproduce the costs of making at any time an equivalent synthetic fuel just from atmospheric $\mathrm{CO}_{2}$ and from $\mathrm{H}_{2} \mathrm{O}$ using exclusively solar energy. Then any later generation could produce the equivalent fuel without having to take recourse to the naturally occurring or depleted fossil fuels. Or even more sensibly, we could start already today to produce all our fuels synthetically. This type of considerations leads to the concept of

2. Internalization of External Costs: The external costs of a product comprise all those hidden costs of a product that sooner or later will burden society. The variety of external costs can be quite staggering: They start out with the repair costs of reconstituting the environment damaged by the side effects of a product or action. They should include wear and tear costs of human installations, such as roads, caused by the usage of the product. Obviously the recycling costs of the constituent parts, when eliminating the product after usage, have to be included as well.

The estimation of the external costs is a highly demanding task which requires research efforts in an extremely broad transdisciplinary field, and more forsight than usually is demanded from scientists, politicians, and managers. But it is a solvable task. Whether the result is after all politically accepted or not is a significantly more difficult question to be answered.

However, I am convinced that these external costs, even when determined by a thoughtful and knowledgeable scientist, do not cover all aspects. There are also far-reaching sociological costs that should be included. For example, selling Coca-Cola in third-world countries should be very heavily taxed because of its detrimental effect on traditional local cultures. Or if a pharmaceutical product is 
brought to the market for a price that can in no way be afforded by average patients in developing countries, it would be fair to raise the price sufficiently in the developed countries to allow for a drastically reduced price in developing countries. One might also raise taxes for low-quality TV broadcasts, for example one million US \$ for each murder shown on screen. One could even consider taxes for all advertisements, irrespective whether their goal is commercial or ideological, because they might irreversibly perturb the traditional cultural equilibrium.

3. Internationalization: A major question in this context remains: who shall raise all these taxes or revenues of the internalized external costs and how shall they be invested to truely undo the damage. Quite obviously, such very heavy environmental taxes can not be collected and managed on a national scale. A revised eco-political system can only function on an international level. In the moment, sufficiently powerful international organizations are completely missing. We have to express at this point the urgent need of much stronger international political and economical agencies which can enforce the necessary measures on a global scale. The academic community with its international scope, knowing no political frontiers, is predestinate to devise sound proposals in this direction.

The fate of the globe cannot be saved by raising taxes alone, it is also necessary to properly invest these revenues in order to take counter-measures against the adverse effects which led to the taxes. It is, for example, by no means clear to me what this implies in the case of robbing fossil fuels from the grounds of Kuwait, Saudi Arabia, or Irak, or selling Coca-Cola to mountain tribes in the Himalaya. Many difficult decisions are to be taken based on knowledge, on a sense of global responsibility, and on ethics, solidarity and compassion.

4. Ethics, Solidarity, and Compassion: I do not believe that a rational economical system that takes into account all conceivable external costs just in monetary terms will be sufficient or even operational. I do not believe that improving the monetary feedback loop is sufficient. If all actions become measurable in monetary units, our world becomes extremely dull and platitudious. One of the few remaining incentives to continue to live would be the pleasure of cheating and of thwarting the inhumane system. Then we are truely back to the beginning. Also international relations merely founded on power politics can not lead to any future stability. - I am convinced that without an ethical drive, the entire human enterprise becomes senseless and we might stop it any time by any suitable means.

But where shall we borrow the indispensible ethical framework from? The traditional churches have lost importance in a rational society because their more fundamentalistic approaches retain little appeal to a critical spirit. And also the great social revolutionaries of the 19th and 20th centuries appear to have lost their former glory. There are no accepted moral grounds left. 
I am convinced that we urgently need a renewed ethics of universal relevance and with a global appeal. Obviously we do not have to invent the contents from scratch. Virtually all relevant and immortal concepts have been expressed and documented over and over again during the past two or more thousand years, and indeed also the Chinese cultural history has made immortal contributions to ethics. All that is necessary is to shape them into a modern, liberal frame work that is compatible with science and with our international obligations.

And is there a more natural birthplace for such a universal ethics than the university itself? I do not expect the sudden appearance of an ingenious and inspired moral philosopher. It will rather be an obligation for the entire academic community to develop and maintain such an ethical framework and to connect it to reality. The university shall become again a spiritual center which combines knowledge, foresight, and social reponsibility. I do not ask for the development of a 'new religion'. In contrary, a liberal attitude and tolerance towards different ways of life and thought is essential. But it seems to me essential that these aspects are openly discussed at universities and in academic circles. If we are once on our way towards such a goal, we will truely become capable of educating scientists and engineers who can carry societal responsibility and are well prepared for demanding functions in society. But I think we should go even a step further.

5. Concepts for a Future Global Community: Science has a global scope since centuries. Economy has become truly global in the course of the past fifty years, and communication seems to have no spatial limits anymore. It is only our nationalistic political structures which are hopelessly old-fashion and in the true sense of the word, narrow-minded. Whether we have to abandon our national shelters and form a single, truly global state or whether it is sufficient to have strong supernational organizations and structures is is still open, in my mind. But I am convinced that much creative, conceptual think ing is necessary to find appropriate international structures that are adapted to the important global functions they have to perform.

The great majority of all severe problems we are faced with are international in nature. The strict adherence of states, even of the most powerful ones, to cosigned agreements and the cosigning of pending agreements are duties of any state which requests respect from others. That there are still major states which did not yet sign the Kyoto Protocol, the Convention on the Right of the Child, the International Criminal Court, the Anti-Land Mine Agreement, and others, is a matter of great shame for those states.

It is certainly one of our obligations as members of the academic community to conceive ways to strengthen the international bodies and agreements, taking advantage of our network of international scientific relations. Again, we can not delegate this task to politologists alone, it is a task for everybody to conceive novel ideas about socio-political international struc tures for the future. We should not expect that changes will be happening rapidly, but we have to condition our young creative generation 
that its members keep in mind the urgency of designing more appropriate structures for our and especially their future.

6. Right of Free Speech: To claim the right of free speech is one thing, but to have the courage to use it under all circumstances is another one. Academics have the obligation to express their views as openly as ever possible. Politicians often can not or do not want to say what they think, as they have to be re-elected. Industrial managers are bound to their company and are not free to express their personal opinions. The members of the academic community, on the other hand, do not have this kind of bounds and can risk more in expressing what they consider to be right. After all, absolute honesty, self-critics, and 'objectivity' are the trade-marks of science.

It is not so much of importance to be always right, than to have a free exchange of opinions. It also includes the strength to admit errors and to correct them whenever necessary. This is the only way of true progress.

7. Benefits for the University: Many of us deplore the fact that in western countries student numbers in the traditional sciences steadily decrease. It seems to become more and more difficult to motivate young people for the exact (and difficult) siences. There may be many reasons for the decreasing fascination. Some of them have to do with the money-mindedness of our time. Becoming wealthy and socially well respected through scientific activities alone may appear to be excessively hard if not impossible. On the other side, more scientific facts than anybody could grasp are already known. Why should we generate even more of these details, seemingly without much direct relevance for the individual and for society? Certainly, it is difficult to favourably impress a girlfriend by a scientific thesis, full of abstract mathe matics, or by a paper published even in the world-best journal. All these activities appear to be detached from the daily activities and the daily enjoyments.

I think it is important to find again a contextual link of the rather esoteric research activities to the life of our fellow-citizens. We might try to better inform the members of society about the relevance of our daily doing so that we scientists become better respected and we gain more public satisfaction. But even more important for our self-respect and our public recognition would be to become again responsible leaders who conceive novel concepts for the sake of our common future regarding social structures and our relation to the enormous technological advances which might lead us to heaven or hell.

I do not believe that it will ever be possible to directly link all our very advanced research themes directly to the global future. I rather think that we scientists have to learn to operate on two levels simultaneously. On the fundamental research level, we have to explore the basic underlying laws of nature. The microscopic aspects of research are truely indispensible. If we do not care about the most minute details, we will not advance the knowledge and we better not even start. But at the same time 
we should develop concep tual activities on a much more coarse-grained level, on a level were a fruitful interaction with politicians and with the general public becomes feasible and fruitful for both sides.

I am sure that studying sciences would become significantly more attractive again for some of our most creative young people when we can offer such an open, intellectually demanding, and at the same time gratifying academic atmosphere. Our young people are not just lazy and pleasure-greedy, but they hate to spoil their precious life for working on seemingly irrelevant details even if it would enable them to make lots of money.

\section{Concluding Remarks}

The function of a university that I have in mind is well described by the term 'agora', market place, a place where ideas are conceived and exchanged, where contacts between all types of people are not only feasible but become reality. But we do not really need a new name, I think that the term 'university', the 'unity formed by all its constituent parts', sufficiently well describes what I and others have in mind. It is important that we break down barriers, barriers between our microscopic scientific view and our concern for a global future, barriers beween the different scientific disciplines and barriers between the inside and the outside of our universities. I am sure that this will become a fertile ground not only for inspiring and creative universities but also for a prosperous future of the entire global society.

You may deplore that I did not present recipes and my own detailed visions for the future of the global society. I thought it more important to emphasize the need for more global responsibility of our universities. I think that a novel kind of awareness will enable us to fruitfully solve relevant problems and make contributions which are sufficiently far-reaching that the university will remain also in the future a central and indispensible institution of our public life.

Perhaps, I may end my lecture by a sentence in french, written almost five hundred years ago by François Rabelais (1494-1553): "Science sans conscience n'est que ruin de l'âme."( "Science without conscience is but the ruin of the soul."). This saying has preserved its validity until today and might be even more important for the future development of science and its relation to society in any country, also in China.

(C) 2003 by MDPI (http://www.mdpi.org). Reproduction is permitted for noncommercial purposes. 